\title{
Significance of an increase in the Child-Pugh score after radiotherapy in patients with unresectable hepatocellular carcinoma
}

Seok Hyun Son ${ }^{1}$, Hong Seok Jang ${ }^{2}$, In-Young Jo ${ }^{1}$, Byung Ock Choi ${ }^{2}$, Jeong Won Jang ${ }^{3}$, Seung Kew Yoon ${ }^{4}$ and Chul Seung Kay ${ }^{1 *}$

\begin{abstract}
Background: We attempted to analyze the effects of an increase in the Child-Pugh (CP) score on the overall survival of patients with unresectable hepatocellular carcinoma (HCC) after radiotherapy (RT).

Methods: From March 2006 to February 2012, 103 patients received RT using the TomoTherapy Hi-Art at Incheon St. Mary's Hospital and Seoul St. Mary's Hospital. The dose per fraction was 1.8-5 Gy, and the total dose was 40-60 Gy (median, 50 Gy). We considered an increase of at least 2 points in the CP score within 3 months after RT to be clinically important radiation-induced hepatic toxicity and analyzed the effects of an increased CP score on overall survival.

Results: The median follow-up duration was 11.6 months (range, 3.5-85.3 months). The median survival time was 11.6 months. In multivariate analysis, planning target volume and an increase in the CP score after RT were found to be a statistically significant factors ( $p=0.010$ and 0.015 , respectively). In a comparison of cases with and without an increase in the CP score, there was an 11.0-month difference in the median survival time (6.9 vs. 17.9 months), and the relative risk of mortality was 1.8 .

Conclusion: An increase of at least 2 points in the CP score within 3 months of RT completion is an important on-treatment factor that affects overall survival. To minimize such increases, careful patient selection and a more sophisticated radiation treatment plan are imperative.
\end{abstract}

Keywords: An increase in Child-Pugh score, Radiotherapy, Unresectable hepatocellular carcinoma

\section{Background}

Radiotherapy (RT) for unresectable hepatocellular carcinoma (HCC) has been used in combination with other local treatments such as transarterial chemoembolization (TACE), percutaneous ethanol injection (PEI), and radiofrequency ablation (RFA) [1-3]. Previously, RT was not widely used because the whole liver could only tolerate low levels of radiation, and these low doses were insufficient to effectively control tumors $[4,5]$. However, recent studies have shown that partial volume irradiation is both feasible and effective for tumor control with an acceptable range of hepatic toxicity [6-8].

\footnotetext{
* Correspondence: k41645@chol.com

'Department of Radiation Oncology, Incheon St. Mary's Hospital, College of Medicine, The Catholic University of Korea, Incheon, Korea

Full list of author information is available at the end of the article
}

Radiation-induced hepatic toxicity (RIHT) in HCC patients must be considered during RT. Currently, there is no effective treatment for RIHT, which can induce liver failure when not appropriately controlled. Thus, RIHT is considered an important dose-limiting toxicity in HCC patients who receive RT [9]. Therefore, studies have attempted to identify predictive parameters to help reduce the incidence of RIHT, and the results have been helpful in the establishment of radiation treatment plans intended to reduce hepatic toxicity during RT [10-19].

The Child-Pugh (CP) score, which is calculated according to the serum albumin and bilirubin levels, the prothrombin time (PT), and the presence and degree of encephalopathy or ascites, is a system for assessing hepatic function. Therefore, an increase in the CP score might reflect deterioration in hepatic function. Additionally, 
an increase in the CP score after RT can cause difficulty in administering additional treatments, disease progression or liver failure, which can affect the patient's prognosis, can be developed [19-21].

In this study, we considered an increase of at least 2 points in the CP score within 3 months after the completion of RT to be an important RIHT. We attempted to analyze the effects of such $\mathrm{CP}$ score increases on the overall survival after RT and to discuss its importance.

\section{Methods}

\section{Patients}

The inclusion criteria for this study were as follows: 1 ) unresectable HCC; 2) age $>18$ years; 3 ) a CP score of 5,6 , or 7 within 1 month before RT; 4) an Eastern Cooperative Oncology Group (ECOG) performance status of 0 or $1 ; 5$ ) an absence of distant metastases; 6) 2 or more laboratory studies within 3 months after the completion of RT; 6) 1 or more radiological studies within 3 months after the completion of RT; and 7) no disease progression within 3 months after the completion of RT.

A total of 103 patients were found to be eligible for this study. All patients received RT using the TomoTherapy Hi-Art system (TomoTherapy Inc., Madison, WI, USA) at Incheon St. Mary's Hospital and Seoul St. Mary's Hospital from March 2006 to February 2012. The patient data were retrospectively reviewed following institutional review board approval (IRB of Incheon St. Mary's Hospital, the Catholic University of Korea, Reference number: OC12RISI0135).

Age, gender, ECOG performance status, American Joint Committee on Cancer (AJCC) stage ( $7^{\text {th }}$ edition), pretreatment CP score, the absence or presence of hepatitis, liver cirrhosis, or portal vein tumor thrombosis (PVTT), the alpha-fetoprotein (AFP) level, and CP score within 3 months after the completion of RT were evaluated. Before RT, TACE was performed in 95 patients (median number of procedures, 2; range, 1-11), PEI in 8 patients (median number of procedures, 2; range, 1-3), RFA in 8 patients (median number of procedures, 2; range, 1-3), and systemic chemotherapy in 14 patients. The patients characteristics are shown in Table 1.

\section{Radiotherapy}

For the simulations, patients were immobilized using the BodyFix system (Medical Intelligence $\mathrm{GmbH}$, Schwabmunchen, Germany), in which the abdomen was compressed under low pressure with foil. Next, a spiral computed tomography (CT) scans were obtained using an intravenous contrast agent and a $2.5-\mathrm{mm}$ slice thickness on either a SOMATOM (Siemens, Berlin, Germany) or a LightSpeed RT16 (GE, Waukesha, WI, USA) CT scanner.

The gross tumor volume (GTV) was defined as the tumor volume that was enhanced in the arterial phase of
Table 1 Clinical characteristics

\begin{tabular}{|c|c|c|}
\hline Variables & n & $(\%)$ \\
\hline \multicolumn{3}{|l|}{ Gender } \\
\hline Male & 80 & 77.7 \\
\hline Female & 23 & 22.3 \\
\hline \multicolumn{3}{|l|}{ Age (year) } \\
\hline Median & 59 & \\
\hline Range & $21-80$ & \\
\hline \multicolumn{3}{|l|}{ ECOG } \\
\hline 0 & 38 & 36.9 \\
\hline 1 & 65 & 63.1 \\
\hline \multicolumn{3}{|l|}{ Hepatitis } \\
\hline None & 2 & 1.9 \\
\hline HBV & 73 & 70.9 \\
\hline $\mathrm{HCV}$ & 9 & 8.7 \\
\hline NBNC & 9 & 8.7 \\
\hline Alcoholic & 10 & 9.7 \\
\hline \multicolumn{3}{|l|}{ Liver cirrhosis } \\
\hline No & 32 & 31.1 \\
\hline Yes & 71 & 68.9 \\
\hline \multicolumn{3}{|l|}{ PVTT } \\
\hline No & 45 & 43.7 \\
\hline Yes & 58 & 56.3 \\
\hline \multicolumn{3}{|l|}{ AFP $(I U / m L)$} \\
\hline$\leq 400$ & 67 & 65.0 \\
\hline$>400$ & 36 & 35.0 \\
\hline \multicolumn{3}{|c|}{ Child-Pugh class before radiotherapy } \\
\hline A & 91 & 88.3 \\
\hline B & 12 & 11.7 \\
\hline \multicolumn{3}{|l|}{ AJCC stage } \\
\hline$\|$ & 14 & 13.6 \\
\hline III & 81 & 78.6 \\
\hline IVA & 8 & 7.8 \\
\hline \multicolumn{3}{|l|}{ Previous treatment } \\
\hline None & 7 & 6.8 \\
\hline TACE & 95 & 92.2 \\
\hline RFA & 8 & 7.8 \\
\hline PEI & 8 & 7.8 \\
\hline Chemotherapy & 14 & 13.6 \\
\hline
\end{tabular}

Abbreviations: ECOG PS Eastern Cooperative Oncology Group performance status, $H B V$ hepatitis $B$ virus, $H C V$ hepatitis $C$ virus, NBNC non-B, non-C, PVTT portal vein tumor thrombosis, AFP alpha-fetoprotein, AJCC American Joint Committee on Cancer, TACE transcarterial chemoembolization, $R F A$ radiofrequency ablation, $P E /$ percutaneous ethanol injection.

the CT scan and diluted in the delayed phase. The planning target volume (PTV) was generated by the addition of 5-15 mm to the GTV in 71 of the 103 patients, which facilitated an asymmetric margin expansion in order to 
reduce irradiation to the stomach, duodenum, and small intestine. In the remaining 32 patients, 4-dimensional (4D) CT was performed to generate an internal target volume in order to compensate for respiration-induced liver movement; these 4D-CT scanners were installed in March 2009 at Seoul St. Mary's Hospital and in March 2011 at Incheon St. Mary's Hospital. The organs at risk, such as the total liver, non-target normal liver (NTNL), stomach, duodenum, intestine, kidney, and spinal cord, were also contoured for evaluation of the irradiated dose. The NTNL volume was the total liver volume minus the PTV.

The GTV was $122.8 \pm 153.3 \mathrm{~cm}^{3}$, the PTV was $330.5 \pm$ $275.1 \mathrm{~cm}^{3}$ and the normal liver volume was $1209.7 \pm$ $426.9 \mathrm{~cm}^{3}$. The dose per fraction to the PTV was 1.8-5 Gy, and the total dose was 40-60 Gy (median, 50 Gy). The dose was prescribed to $95 \%$ of the PTV. The treatment characteristics are shown in Table 2. The prescribed dose varied according to the pretreatment $\mathrm{CP}$ class and the PTV. When the PTV was small and the pretreatment $\mathrm{CP}$ class was $\mathrm{A}$, the prescribed dose was higher and 4-5 Gy per fraction was used. When the PTV was large or the pretreatment $\mathrm{CP}$ class was $\mathrm{B}$, the prescribed dose was lower and 1.8-2.5 Gy per fraction was used. Additionally, normal tissue constraints, which were used in our institution at the time of the study, were applied (Table 3). We intended to prescribe the PTV dose according to the normal tissue constraints; however, these constraints were not always satisfied in order to achieve adequate target coverage and proper tumor dose. Treatment planning was performed using the built-in software of the TomoTherapy Planning Station, which was used with the

Table 2 Treatment characteristics

\begin{tabular}{ll}
\hline Variables & \\
\hline GTV $\left(\mathrm{cm}^{3}\right)$ & $122.8 \pm 153.3$ \\
PTV $\left(\mathrm{cm}^{3}\right)$ & $330.5 \pm 275.1$ \\
Normal liver volume $\left(\mathrm{cm}^{3}\right)$ & $1209.7 \pm 426.9$ \\
Total dose (Gy) & 50 \\
$\quad$ Median & $40-60$ \\
$\quad$ Range & \\
BED10 (Gy $)$ & 73.5 \\
$\quad$ Median & $50.5-82.5$ \\
$\quad$ Range & \\
EQD2 (Gy, a/ $\beta$ ratio = 10) & 61.3 \\
$\quad$ Median & $42.1-68.8$ \\
$\quad$ Range & \\
Hypofractionation (n,\%) & $41(39.8 \%)$ \\
1.8-2.5 Gy per fraction & $62(60.2 \%)$ \\
\hline
\end{tabular}

Abbreviations: GTV gross tumor volume, PTV planning target volume, $B E D$ biologically effective dose, EQD2 equivalent dose in 2-Gy fractions.
TomoTherapy Hi-Art system. We evaluated the dosevolume histogram (DVH) and dose distributions in a slice-by-slice manner. We then approved the treatment plan if tumor coverage was adequate and doses to the surrounding normal tissue were within acceptable levels. Megavoltage cone-beam CT was performed during each treatment session before actual beam delivery. Patients' set-up and position were corrected using automated image registration, and anatomical accuracy was always evaluated by a radiation oncologist.

\section{Evaluation and analysis}

We considered an increase of at least 2 points in the $\mathrm{CP}$ score within 3 months after the completion of RT to be a clinically important RIHT. The CP score, which is calculated according to the serum bilirubin and albumin levels, the PT, and the presence and degree of ascites or encephalopathy, is used as a tool to assess hepatic function; thus, an increase in the CP score reflects deterioration in the hepatic function $[19,21]$.

The effects of clinical factors, including age, gender, ECOG performance status, the presence or absence of liver cirrhosis, hepatitis, PVTT, AFP level, pretreatment $\mathrm{CP}$ class, and PTV, on overall survival were analyzed. The effects of treatment factors, including the biologically effective dose (BED) and fraction size, on overall survival were also analyzed. Furthermore, the effect of an increase of at least 2 points in the $\mathrm{CP}$ score within 3 months after RT completion on overall survival after RT was analyzed.

\section{Statistical analyses}

Overall survival was calculated from the date of RT to the date of death or the last follow-up. The probability of cumulative survival was calculated according to the Kaplan-Meier method. Univariate and multivariate analyses were performed according to the Cox proportional hazards models. Multivariate analysis was performed according to the "enter" method. Significant variables in univariate analysis were included in multivariate analysis. The association between the clinical/tumor characteristics and an increase in the CP score was analyzed using the chi-square test and independent t-test. The statistical analysis were performed using STATA 12.1 software (StataCorp, College Station, TX, USA), and $p$ values of $<0.05$ were considered statistically significant.

\section{Results}

\section{Overall survival and clinical factors that influence the survival}

The median follow-up duration was 11.6 months (range, 3.5-85.3 months). The median survival time was 11.6 months, and the 1-, 2-, and 3-year survival rates were $48.5 \%, 23.4 \%$, and $14.3 \%$, respectively. In univariate 
Table 3 Normal tissue constraints

\begin{tabular}{llll}
\hline & $\mathbf{1 . 8 - 2 . 0}$ Gy per fraction & $\mathbf{2 . 5 - 3 . 0 ~ G y ~ p e r ~ f r a c t i o n ~}$ & 4.0-5.0 Gy per fraction \\
\hline Liver & $T L-V_{30 G y}<60 \%$ & & $T L-V_{20 G y}<60 \%$ \\
Kidney & Mean dose $<31 \mathrm{~Gy}$ & Mean dose $<30 \mathrm{~Gy}$ & Mean dose $<22 \mathrm{~Gy}$ \\
Spinal cord & $\mathrm{V}_{18 G y}<33 \%$ & Mean dose $<16 \mathrm{~Gy}$ & Mean dose $<13 \mathrm{~Gy}$ \\
Intestine & $\mathrm{D}_{2 c c}<45 \mathrm{~Gy}$ & $\mathrm{D}_{2 c c}<42 \mathrm{~Gy}$ & $\mathrm{D}_{2 c c}<33 \mathrm{~Gy}$ \\
\hline
\end{tabular}

Abbreviations: $T L$ total liver, $V_{30 G y}$ volume of normal tissue that receives more than $30 \mathrm{~Gy}, D_{2 c c}$ maximal dose to 2 cc of normal tissue.

analysis, pretreatment $\mathrm{CP}$ class $\mathrm{B}, \mathrm{PTV}$ more than $225 \mathrm{~cm}^{3}$, and an increase of at least 2 points in CP score after RT were found to be statistically significant unfavorable factors for overall survival $(p=0.038,0.001$, and $p<0.001$, respectively). Gender, age, ECOG performance status, AJCC stage, the level of AFP, the presence or absence of liver cirrhosis, hepatitis, PVTT, BED, and hypofractionation were not found to be statistically significant factors. In multivariate analysis, PTV more than $225 \mathrm{~cm}^{3}$ and an increase of at least 2 points in the CP score after RT were found to be statistically significant factors for poor overall survival ( $p=0.010$ and 0.015 , respectively). The results of univariate and multivariate analyses are summarized in Table 4.

The associations between the clinical/tumor characteristics and an increase of at least 2 points in the CP score are summarized in Table 5. PVTT $(p=0.027)$ and PTV $(p<0.001)$ were significantly associated with an increase in

Table 4 Predictive factors that influence the overall mortality

\begin{tabular}{|c|c|c|c|c|}
\hline \multirow[t]{2}{*}{ Variables } & \multicolumn{2}{|c|}{ Univariate analysis } & \multicolumn{2}{|c|}{ Multivariate analysis } \\
\hline & HR $(95 \% \mathrm{Cl})$ & $\overline{p \text { value }}$ & $\mathrm{HR}(95 \% \mathrm{Cl})$ & $\overline{p \text { value }}$ \\
\hline \multirow[t]{2}{*}{ Gender (female) } & 1.329 & 0.262 & & \\
\hline & $(0.807-2.192)$ & & & \\
\hline \multirow[t]{2}{*}{ Age } & 1.002 & 0.826 & & \\
\hline & $(0.982-1.023)$ & & & \\
\hline \multirow[t]{2}{*}{ ECOG PS (1) } & 1.052 & 0.816 & & \\
\hline & $(0.686-1.613)$ & & & \\
\hline \multirow[t]{2}{*}{ Hepatitis (B) } & 1.068 & 0.780 & & \\
\hline & $(0.672-1.697)$ & & & \\
\hline \multirow[t]{2}{*}{ Liver cirrhosis (presence) } & 1.371 & 0.175 & & \\
\hline & $(0.868-2.164)$ & & & \\
\hline \multirow[t]{2}{*}{ PVTT (presence) } & 1.457 & 0.079 & & \\
\hline & $(0.957-2.217)$ & & & \\
\hline \multirow[t]{2}{*}{$\operatorname{AFP}(>400)$} & 1.798 & 0.083 & & \\
\hline & $(0.926-3.484)$ & & & \\
\hline \multirow[t]{2}{*}{ Pretreatment CP class (B) } & 1.834 & 0.038 & 1.524 & 0.255 \\
\hline & $(1.033-3.257)$ & & $(0.738-3.144)$ & \\
\hline \multirow[t]{2}{*}{ PTV $\left(>225 \mathrm{~cm}^{3}\right)$} & 2.057 & 0.001 & 1.821 & 0.010 \\
\hline & $(1.355-3.125)$ & & $(1.157-2.865)$ & \\
\hline \multirow[t]{2}{*}{ BED (>70 Gy) } & 0.839 & 0.448 & & \\
\hline & $(0.532-1.322)$ & & & \\
\hline \multirow[t]{2}{*}{ Hypofractionation ( $\geqq 4$ Gy per fraction) } & 0.731 & 0.146 & & \\
\hline & $(0.479-1.116)$ & & & \\
\hline \multirow[t]{2}{*}{ An increase in CP score after RT $(\geq 2)$} & 2.283 & $<0.001$ & 1.795 & 0.015 \\
\hline & $(1.494-3.484)$ & & $(1.121-2.881)$ & \\
\hline
\end{tabular}


Table 5 Clinical and tumor characteristics assosiated with an increase in $\mathrm{CP}$ score

\begin{tabular}{|c|c|c|c|}
\hline Variables & No toxicity & Toxicity & $p$ value \\
\hline \multicolumn{4}{|l|}{ Gender } \\
\hline Male & 45 & 35 & 0.475 \\
\hline Female & 11 & 12 & \\
\hline \multicolumn{4}{|l|}{ Age } \\
\hline Median & 60 & 57 & 0.142 \\
\hline Range & $21-80$ & $40-80$ & \\
\hline \multicolumn{4}{|l|}{ ECOG PS } \\
\hline 0 & 18 & 20 & 0.275 \\
\hline 1 & 38 & 27 & \\
\hline \multicolumn{4}{|l|}{ Hepatitis } \\
\hline B & 40 & 33 & 0.892 \\
\hline Others & 16 & 14 & \\
\hline \multicolumn{4}{|c|}{ Liver cirrhosis } \\
\hline No & 19 & 13 & 0.493 \\
\hline Yes & 37 & 34 & \\
\hline \multicolumn{4}{|l|}{ PVIT } \\
\hline No & 30 & 15 & 0.027 \\
\hline Yes & 26 & 32 & \\
\hline \multicolumn{4}{|l|}{ AFP } \\
\hline$\leq 400$ & 40 & 27 & 0.138 \\
\hline$>400$ & 16 & 20 & \\
\hline
\end{tabular}

Pretreatment CP class

$\begin{array}{lccc}\text { A } & 52 & 39 & 0.120 \\ \text { B } & 4 & 8 & \\ \text { PTV } & & & \\ \quad \leq 225 \mathrm{~cm}^{3} & 42 & 18 & <0.001 \\ >225 \mathrm{~cm}^{3} & 14 & 29 & \\ \text { BED } & & & \\ \quad \leq 70 \text { Gy } & 22 & 27 & 0.066 \\ >70 \text { Gy } & 34 & 20 & \end{array}$

Hypofractionation

$\begin{array}{llll}<4 \text { Gy per fraction } & 39 & 24 & 0.054 \\ \geq 4 \text { Gy per fraction } & 17 & 23\end{array}$

Abbreviations: HR hazard ratio, Cl confidence interval, ECOG PS Eastern Cooperative Oncology Group performance status, PVTT portal vein tumor thrombosis, AFP alpha-fetoprotein, CP Child-Pugh, PTV planning target volume, $B E D$ biologically effective dose.

the CP score. BED $(p=0.066)$ and hypofractionation $(p=0.054)$ were marginally significant factors that influenced an increase in the CP score.

\section{Significance of an increase at least 2 points in CP score after the completion of radiotherapy}

An increase of at least 2 points in the $\mathrm{CP}$ score was noted in 47 of the 103 patients (45.6\%) after a median time of 1.7 months (range, 0.8-3.0 months) after RT completion. Among these 47 patients, 5 patients (10.6\%) recovered from a $\mathrm{CP}$ score increase after a median time of 2.73 months (range, 2.53-3.0 months) after RT completion. However, such recoveries were transient because the $\mathrm{CP}$ scores increased again after a median time of 0.9 months (range, $0.13-1.13$ months). In the absence of an increase of at least 2 points in the $\mathrm{CP}$ score, the median survival time was 17.9 months, and the 1-, 2-, and 3 -year survival rates were $66.1 \%, 34.7 \%$, and $22.1 \%$, respectively. In the presence of an increase of at least 2 points in the $\mathrm{CP}$ score, the median survival time was 6.9 months, and the 1-, 2-, and 3-year survival rates were $27.7 \%, 10.2 \%$, and $5.1 \%$, respectively (Figure 1). In a comparison between cases with increased CP scores and those without increased CP scores, there was an 11.0month difference in the median survival time (6.9 vs. 17.9 months), and the relative risk of mortality was 1.8 .

An increase of at least 2 points in the CP score was significantly associated with the number of TACE procedures after RT. TACE could be performed after RT in 64 of 103 patients (62.1\%). In cases with no increase in the CP score, the number of TACE procedures was $2.2 \pm 2.8$; however, in cases with an increase in the $\mathrm{CP}$ score, the number of TACE procedures was $1.1 \pm 1.1$, and this difference was statistically significant $(p=0.01)$. When the analysis was limited to patients who underwent TACE, the number of TACE procedures in patients without an increased $\mathrm{CP}$ score $(3.7 \pm 2.7)$ was significantly higher than that in patients with an increased $\mathrm{CP}$ score $(1.7 \pm 0.9)$; this

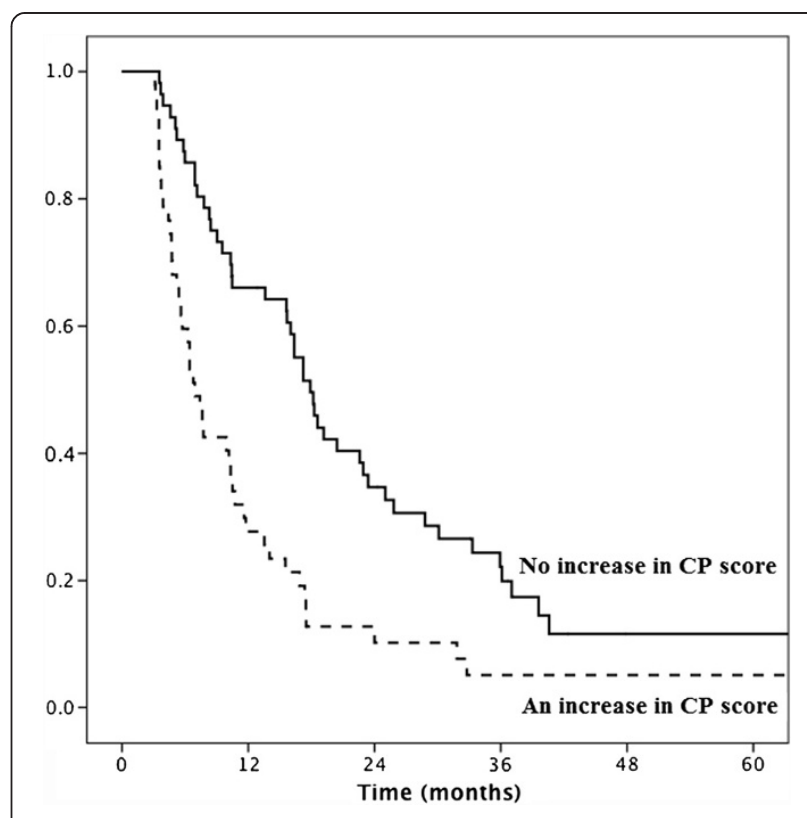

Figure 1 Survival curves according to the presence or absence of an increase in the CP score. 
difference was statistically significant $(p<0.001)$. RFA and PEI were performed in 3 and 2 patients, respectively, after $\mathrm{RT}$, and none of these patients experienced an increase in the CP score.

\section{Discussion}

RIHT is an important dose-limiting toxicity in HCC patients that must be considered during RT. Studies have sought predictive factors such as dose-volumetric parameters based on $\mathrm{DVH}$, and these parameters and their values are being used to establish radiation treatment plans. However, the definition of RIHT has varied in previous studies. Radiation-induced liver disease (RILD) is a traditionally accepted concept of hepatic toxicity. Classic RILD is a subacute hepatic toxicity that presents with anicteric ascites, hepatomegaly, and elevated alkaline phosphatase levels; it typically occurs between 4 and 8 weeks after the completion of RT [5,22]. Previously, classic RILD was a serious problem that could occur in response to radiation amounts of 30-35 Gy to the whole liver; however, the incidence decreased after partial volume irradiation became more frequently used $[13,14]$. Kim et al. [10] considered an increase in hepatic enzymes above grade 2 to be RIHT according to the Common Terminology Criteria for Adverse Events (CTCAE) criteria. Dawson et al. [18] considered an increase in hepatic enzymes above grade 3 to be RIHT, according to the Radiation Therapy Oncology Group toxicity criteria. Liang et al. [12], Lee et al. [15], and Cheng et al. [16] considered hepatic enzyme levels higher than CTCAE grade 3 to be RIHT and accordingly suggested predictive parameters and their values.

The increase in hepatic enzyme level is temporary, and thus, the levels recover within a few months [10]. In our previous study, the increase in hepatic enzymes could not be appropriately viewed as a dose-limiting toxicity [14]. According to Furuse et al. [20], hypoalbuminemia, hyperbilirubinemia, and ascites are important hepatic events that can occur after RT for HCC treatment, and these events can considerably affect patient survival. Albumin, bilirubin, and ascites are the factors used to calculate the $\mathrm{CP}$ score. Furthermore, an earlier study stated that progression of the $\mathrm{CP}$ class is a useful dose-limiting factor with which to predict the deterioration of hepatic function [14]. An increase of at least 2 points in the CP score was used to evaluate hepatic function deterioration in patients who were treated with lamivudine by Liaw et al. [21], and to find a predictive parameter in patients who were treated with helical tomotherapy by Son et al. [19]. For this reason, the CP score is appropriate for evaluation of hepatic function, and an increase of at least 2 points in the $\mathrm{CP}$ score can be viewed as an important factor with which to evaluate hepatic toxicity after RT. Moreover, classic RILD and RIHT-related studies report the occurrence of this toxicity within 3-4 months $[10,11,13,17,22]$. Therefore, it is reasonable to consider an increase of at least 2 points in the $\mathrm{CP}$ score within 3 months to be RIHT.

However, an increased CP score could occur in response to natural deterioration of the underlying liver cirrhosis, tumor progression, and HCC treatment. To minimize the effects of these events on the $\mathrm{CP}$ score, a pretreatment CP score of 5-7, an ECOG performance status of $0-1$ and the absence of disease progression within 3 months were used as inclusion criteria. Furthermore, the $\mathrm{CP}$ score was monitored for 3 months. Although a shorter follow-up duration for the CP score after the completion of RT could reduce the risk of influence of natural deterioration of liver cirrhosis, a 3-month follow-up duration was necessary in order to evaluate RT-induced CP score increases according to previous studies $[10,11,13,17,19]$. Moreover, we evaluated the laboratory results immediately prior to other treatments to prevent errors caused by the transient elevation of $\mathrm{CP}$ scores if additional treatments were performed within the 3-month period after RT.

In our study, PTV of $225 \mathrm{~cm}^{3}$ and an increased CP score were found to be significant factors that affected overall survival in multivariate analysis. The pretreatment CP class was a significant factor in univariate analysis, but not in multivariate analysis $(p=0.353)$. According to Cheng et al. [16], the risk of RIHT was high in cases of CP class B, and Liang et al. [12] reported that the incidence of RIHT was higher in cases of CP class B than in cases of CP class A. However, in a study by Yoon et al. [23], the pretreatment CP class was determined to be a factor that affects prognosis in univariate analysis, but not in multivariate analysis. Larger tumor size is a well-known poor prognostic factor in terms of tumor responsiveness or overall survival $[6,23,24]$. In our study, an increase of at least 2 points in the CP score after the completion of RT was found to be a significant factor instead of the pretreatment $\mathrm{CP}$ class. In a comparison of cases with and without an increase in $\mathrm{CP}$ score, there was an 11.0-month difference in the median survival time (6.9 vs. 17.9 months), and the relative risk of mortality was 1.8. In a study of Liang et al. [13], there was an 18-month difference in the median survival time, which depend on the presence of RILD (4 vs. 22 months). Thus, in that study, the difference in the median survival time was larger than the difference in our study, and the median survival time for the group with hepatic toxicity was shorter (4 months in Liang et al. vs. 6.9 months in this study). This might be because Liang et al.'s definition of hepatic toxicity was different from ours. Nonetheless, our results are similar in the sense that they show the importance of preventing such toxicity, because the overall survival is low in patients with hepatic toxicity. 
Moreover, in this study, the number of TACE procedures performed after RT differed according to whether there was an increase in the $\mathrm{CP}$ score $(3.7 \pm 2.7$ vs. $1.7 \pm$ 0.9 times). This could be interpreted to mean that there were fewer opportunities for additional treatments because of hepatic function deterioration in the group with increased CP scores. Unresectable HCC is difficult to treat completely with RT alone; therefore, treatments such as TACE are repeatedly performed to obtain the maximum effect. However, if it becomes difficult to administer such procedures because of hepatic function deterioration, patient survival may be adversely affected because there are few other opportunities to control tumor progression.

In conclusion, an increase of at least 2 points in the $\mathrm{CP}$ score within 3 months of RT completion is an important on-treatment factor that affects overall survival. To minimize such increases, careful patient selection and a more sophisticated radiation treatment plan are imperative.

\section{Competing interests}

The authors declare that they have no competing interests.

\section{Authors' contributions}

SHS, CSK, IJ, BOC, and HSJ collected the clinical data and interpreted the results. SHS, CSK, HSJ, JWJ, and SKY cared for the patients. SHS, CSK, JWJ, SKY, and HSJ were involved in the study design. SHS performed the statistical analysis and drafted the manuscript. All of the authors have read and approved the final draft.

\section{Author details}

'Department of Radiation Oncology, Incheon St. Mary's Hospital, College of Medicine, The Catholic University of Korea, Incheon, Korea. ${ }^{2}$ Department of Radiation Oncology, Seoul St. Mary's Hospital, College of Medicine, The Catholic University of Korea, Seoul, Korea. ${ }^{3}$ Department of Internal Medicine, Incheon St. Mary's Hospital, College of Medicine, The Catholic University of Korea, Incheon, Korea. ${ }^{4}$ Department of Internal Medicine, Seoul St. Mary's Hospital, College of Medicine, The Catholic University of Korea, Seoul, Korea.

Received: 24 August 2013 Accepted: 21 April 2014

Published: 29 April 2014

\section{References}

1. Camma C, Schepis F, Orlando A, Albanese M, Shahied L, Trevisani F, Andreone P, Craxi A, Cottone M: Transarterial chemoembolization for unresectable hepatocellular carcinoma: meta-analysis of randomized controlled trials. Radiology 2002, 224(1):47-54

2. Lencioni R, Pinto F, Armillotta N, Bassi AM, Moretti M, Di Giulio M, Marchi S, Uliana M, Della Capanna S, Lencioni M, Bartolozzi C: Long-term results of percutaneous ethanol injection therapy for hepatocellular carcinoma in cirrhosis: a European experience. Eur Radiol 1997, 7(4):514-519.

3. Solbiati L, Livraghi T, Goldberg SN, lerace T, Meloni F, Dellanoce M, Cova L, Halpern EF, Gazelle GS: Percutaneous radio-frequency ablation of hepatic metastases from colorectal cancer: long-term results in 117 patients. Radiology 2001, 221(1):159-166.

4. Cochrane AM, Murray-Lyon IM, Brinkley DM, Williams R: Quadruple chemotherapy versus radiotherapy in treatment of primary hepatocellular carcinoma. Cancer 1977, 40(2):609-614.

5. Lawrence TS, Robertson JM, Anscher MS, Jirtle RL, Ensminger WD, Fajardo LF: Hepatic toxicity resulting from cancer treatment. Int I Radiat Oncol Biol Phys 1995, 31(5):1237-1248.

6. Park W, Lim DH, Paik SW, Koh KC, Choi MS, Park CK, Yoo BC, Lee JE, Kang MK, Park YJ, Nam HR, Ahn YC, Huh SJ: Local radiotherapy for patients with unresectable hepatocellular carcinoma. Int J Radiat Oncol Biol Phys 2005, 61(4):1143-1150
7. Cheng JC, Chuang VP, Cheng SH, Huang AT, Lin YM, Cheng TI, Yang PS, You DL, Jian JJ, Tsai SY, Sung JL, Horng CF: Local radiotherapy with or without transcatheter arterial chemoembolization for patients with unresectable hepatocellular carcinoma. Int J Radiat Oncol Biol Phys 2000, 47(2):435-442.

8. Seong J, Keum KC, Han KH, Lee DY, Lee JT, Chon CY, Moon YM, Suh CO, Kim GE: Combined transcatheter arterial chemoembolization and local radiotherapy of unresectable hepatocellular carcinoma. Int J Radiat Oncol Biol Phys 1999, 43(2):393-397.

9. Okuda K, Ohtsuki T, Obata H, Tomimatsu M, Okazaki N, Hasegawa H, Nakajima Y, Ohnishi K: Natural history of hepatocellular carcinoma and prognosis in relation to treatment. Study of 850 patients. Cancer 1985, 56(4):918-928.

10. Kim TH, Kim DY, Park JW, Kim SH, Choi Jl, Kim HB, Lee WJ, Park SJ, Hong EK, Kim CM: Dose-volumetric parameters predicting radiation-induced hepatic toxicity in unresectable hepatocellular carcinoma patients treated with three-dimensional conformal radiotherapy. Int I Radiat Oncol Biol Phys 2007, 67(1):225-231.

11. Dawson LA, Normolle D, Balter JM, McGinn CJ, Lawrence TS, Ten Haken RK: Analysis of radiation-induced liver disease using the Lyman NTCP model. Int J Radiat Oncol Biol Phys 2002, 53(4):810-821.

12. Liang $S X$, Zhu XD, Xu ZY, Zhu J, Zhao JD, Lu HJ, Yang YL, Chen L, Wang AY, Fu XL, Jiang GL: Radiation-induced liver disease in three-dimensional conformal radiation therapy for primary liver carcinoma: the risk factors and hepatic radiation tolerance. Int I Radiat Oncol Biol Phys 2006, 65(2):426-434

13. Liang S, Huang X, Zhu X, Zhang W, Cai L, Huang H, Li Y, Chen L, Liu M: Dosimetric predictor identification for radiation-induced liver disease after hypofractionated conformal radiotherapy for primary liver carcinoma patients with Child-Pugh Grade A cirrhosis. Radiother Oncol 2011, 98(2):265-269.

14. Son SH, Choi BO, Ryu MR, Kang YN, Jang JS, Bae SH, Yoon SK, Choi IB, Kang KM, Jang HS: Stereotactic body radiotherapy for patients with unresectable primary hepatocellular carcinoma: dose-volumetric parameters predicting the hepatic complication. Int I Radiat Oncol Biol Phys 2010, 78(4):1073-1080

15. Lee IJ, Seong J, Shim SJ, Han KH: Radiotherapeutic parameters predictive of liver complications induced by liver tumor radiotherapy. Int I Radiat Oncol Biol Phys 2009, 73(1):154-158.

16. Cheng JC, Wu JK, Huang CM, Liu HS, Huang DY, Cheng SH, Tsai SY, Jian JJ, Lin YM, Cheng TI, Horng CF, Huang AT: Radiation-induced liver disease after three-dimensional conformal radiotherapy for patients with hepatocellular carcinoma: dosimetric analysis and implication. Int J Radiat Oncol Biol Phys 2002, 54(1):156-162.

17. Cheng J, Wu J, Lee P, Liu H, Jian J, Lin Y, Sung J, Jan G: Biologic susceptibility of hepatocellular carcinoma patients treated with radiotherapy to radiation-induced liver disease. Int I Radiat Oncol Biol Phys 2004, 60:1502-1509.

18. Dawson LA, Biersack M, Lockwood G, Eisbruch A, Lawrence TS, Ten Haken RK: Use of principal component analysis to evaluate the partial organ tolerance of normal tissues to radiation. Int I Radiat Oncol Biol Phys 2005, 62(3):829-837

19. Son SH, Kay CS, Song JH, Lee SW, Choi BO, Kang YN, Jang JW, Yoon SK, Jang HS: Dosimetric parameter predicting the deterioration of hepatic function after helical tomotherapy in patients with unresectable locally advanced hepatocellular carcinoma. Radiat Oncol 2013, 8:11.

20. Furuse J, Ishii H, Nagase $M$, Kawashima M, Ogino T, Yoshino M: Adverse hepatic events caused by radiotherapy for advanced hepatocellular carcinoma. J Gastroenterol Hepatol 2005, 20(10):1512-1518.

21. Liaw Y, Sung JJ, Chow WC, Farrell G, Lee C, Yuen H, Tanwandee T, Tao Q, Shue K, Keene ON, Dixon JS, Gray DF, Sabbat J, Cirrhosis Asian Lamivudine Multicentre Study Group: Lamivudine for patients with chronic hepatitis B and advanced liver disease. N Engl J Med 2004, 351(15):1521-1531.

22. Ogata K, Hizawa K, Yoshida M, Kitamuro T, Akagi G, Kagawa K, Fukuda F: Hepatic injury following irradiation-a morphologic study. Tokushima $J$ Exp Med 1963, 43:240-251.

23. Yoon SM, Lim Y, Won HJ, Kim JH, Kim KM, Lee HC, Chung Y, Lee YS, Lee SG, Park JH, Suh DJ: Radiotherapy plus transarterial chemoembolization for 
hepatocellular carcinoma invading the portal vein: long-term patient outcomes. Int J Radiat Oncol Biol Phys 2012, 82(5):2004-2011.

24. Kwon JH, Bae SH, Kim JY, Choi BO, Jang HS, Jang JW, Choi JY, Yoon SK, Chung KW: Long-term effect of stereotactic body radiation therapy for primary hepatocellular carcinoma ineligible for local ablation therapy or surgical resection. Stereotactic radiotherapy for liver cancer. Radiat Oncol 2010, 10:475.

doi:10.1186/1748-717X-9-101

Cite this article as: Son et al:: Significance of an increase in the Child-

Pugh score after radiotherapy in patients with unresectable

hepatocellular carcinoma. Radiation Oncology 2014 9:101.

\section{Submit your next manuscript to BioMed Central and take full advantage of:}

- Convenient online submission

- Thorough peer review

- No space constraints or color figure charges

- Immediate publication on acceptance

- Inclusion in PubMed, CAS, Scopus and Google Scholar

- Research which is freely available for redistribution 